\title{
Prolapso de gordura orbitária e oftalmopatia de Graves
}

\section{Orbital fat prolapse and Graves' ophthalmopathy}

Kim-Ir-Sen Santos Teixeira', Rachel Campêlo Feres², Gustavo Maurílio do Nascimento Garcia Pereira', Marise Amaral Rebouças Moreira ${ }^{4}$, Dorislay Barbosa de Sousa Camargo Andrade

RESUMO
Relatam-se dois casos clínicos de prolapso de gordura orbitária, sendo um associado à
oftalmopatia de Graves. Os pacientes apresentavam em comum exame clínico com
elevação na região temporal da órbita direita e aumento da gordura intraorbitária na
tomografia computadorizada de órbitas. No caso da paciente com oftalmopatia de Gra-
ves observou-se também aumento do volume da musculatura orbital no exame de
imagem. O trabalho busca incluir a oftalmopatia de Graves, quando nesta ocorre au-
mento da gordura orbital como diagnóstico diferencial do prolapso de gordura orbitária.

Descritores: Oftalmopatia; Doença de Graves; Doenças da órbita; Oftalmopatia de Graves; Prolapso; Tecido adiposo; Relatos de casos

\footnotetext{
'Doutor, Professor adjunto do Departamento de Patologia, Radiologia e Diagnóstico por Imagem da Faculdade de Medicina da Universidade Federal de Goiás - UFG - Goiânia (GO), Brasil;

2 Acadêmica da Faculdade de Medicina da Universidade Federal de Goiás - UFG - Goiânia (GO), Brasil;

3 Médico oftalmologista do Hospital da Visão de Goiânia - Goiânia (GO), Brasil;

${ }^{4}$ Doutora, Professora Adjunta do Departamento de Patologia, Radiologia e Diagnóstico por Imagem da Faculdade de Medicina da Universidade Federal de Goiás - UFG - Goiânia (GO), Brasil;

${ }^{5}$ Médica Oftalmologista do Centro Especializado da Visão de Goiânia - Goiânia (GO), Brasil.
}

Trabalho realizado na Faculdade de Medicina da Universidade Federal de Goiás.

Recebido para publicação em: 17/10/2008 - Aceito para publicação em 26/3/2009 


\section{INTRODUÇãO}

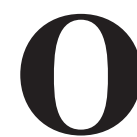
prolapso de gordura orbitária e a oftalmopatia de Graves são entidades clínicas distintas. Ocorrem respectivamente por enfraquecimento do septo orbitário ${ }^{(1.5)} \mathrm{e}$ infiltração celular inflamatória ${ }^{(6)}$. Apesar de possuírem etiologias diferentes, ambas podem se manifestar clinicamente de forma semelhante e com aumento da gordura intraorbitária na tomografia computadorizada das órbitas. Relatam-se dois casos clínicos dessas entidades, incluindo a oftalmopatia de Graves como diagnóstico diferencial do prolapso de gordura orbitária.

\section{Relato de caso}

\section{Caso 1}

Paciente do sexo masculino, 59 anos, cor branca, queixando-se de uma elevação no canto externo da órbita direita há dois anos. Não havia história prévia de trauma, infecção, inflamação ou tratamento cirúrgico nessa órbita. A elevação causava desconforto à movimentação ocular, além da queixa estética relatada pelo paciente. Na ectoscopia mostrava-se aproximadamente com $10 \mathrm{~mm}$, levemente amarelada, móvel, arredondada, homogênea, com vasos sanguíneos e sem sinais de flogose (Figura 1A).

A tomografia computadorizada das órbitas verificou imagem de hipoatenuação adiposa projetando-se imediatamente acima do músculo reto lateral direito $\mathrm{e}$ entre o músculo reto superior deste lado (Figura 2A). A ressonância magnética evidenciou aumento de volume da gordura do espaço intraconal aparentemente herniado $12 \mathrm{~mm}$, no canto temporal da órbita direita (Figura 3).

Com o diagnóstico de prolapso de gordura orbitária no canto temporal superior da órbita direita, o

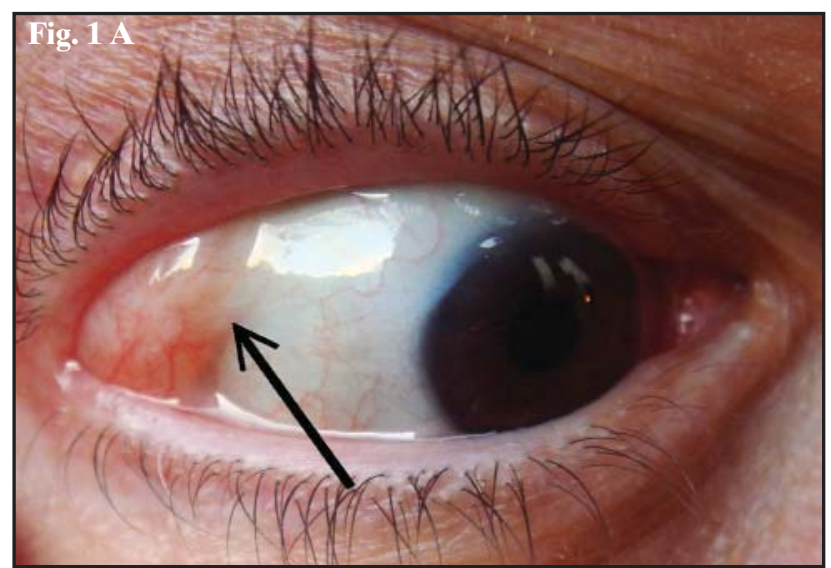

paciente foi submetido à ressecção cirúrgica e o material encaminhado ao exame histopatológico. $\mathrm{Na}$ microscopia identificou-se fragmento de tecido adiposo com adipócitos maduros sem atipias, capilares congestos e ausência de sinais de malignidade (Figura 4).

\section{Caso 2}

Paciente do sexo feminino, 78 anos, cor branca, queixando-se de uma elevação, há oito meses, na região temporal da órbita direita. Relatava também história de cirurgia para correção de catarata. $\mathrm{Na}$ ectoscopia notava-se um nódulo de aproximadamente $13 \mathrm{~mm}$ na região relatada, móvel, amarelado, indolor, arredondado, homogêneo,com vasos sanguíneos e sem sinais flogísticos (Figura 1B).

A tomografia computadorizada de órbitas foi compatível com oftalmopatia de Graves, evidenciando leve proptose bilateral, sinais de manipulação cirúrgica nos cristalinos, espessamento difuso e simétrico da musculatura extrínseca e aumento da gordura intra-orbitária bilateralmente, sendo este mais evidente no canto súperolateral da órbita direita (Figura 2B).

Foram então solicitados os exames de função tireoidiana (T3 e T4 livre), dosagem do hormônio tireoestimulante e do antirreceptor do TSH-TRAB sendo todos os resultados normais.

\section{Discussão}

A gordura orbitária envolve todas as estruturas da órbita e é contida pela cápsula de Tenon e septo orbitário ${ }^{(25,7)}$. Com o envelhecimento ocorre enfraquecimento do septo orbitário causando prolapso da gordura intraorbitária ${ }^{(1.5)}$, normalmente localizado na região temporal da órbita ${ }^{(3-5)}$. Ao exame, o prolapso de gordura orbitária caracteriza-se por elevação amarelada, homo-

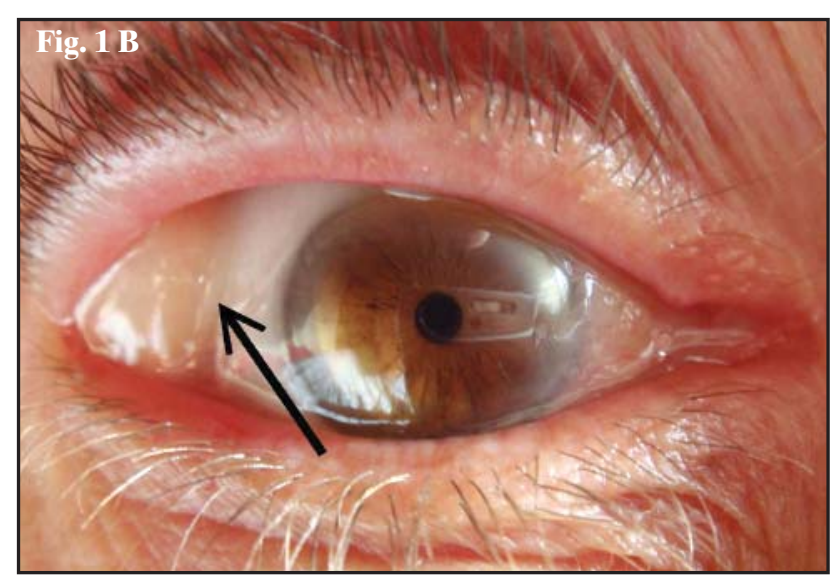

Figura 1: Prolapso de gordura orbitária (setas) na região temporal do olho direito (A) Caso 1 e (B) Caso 2; Não são visualizadas outras alterações da oftalmopatia de Graves 


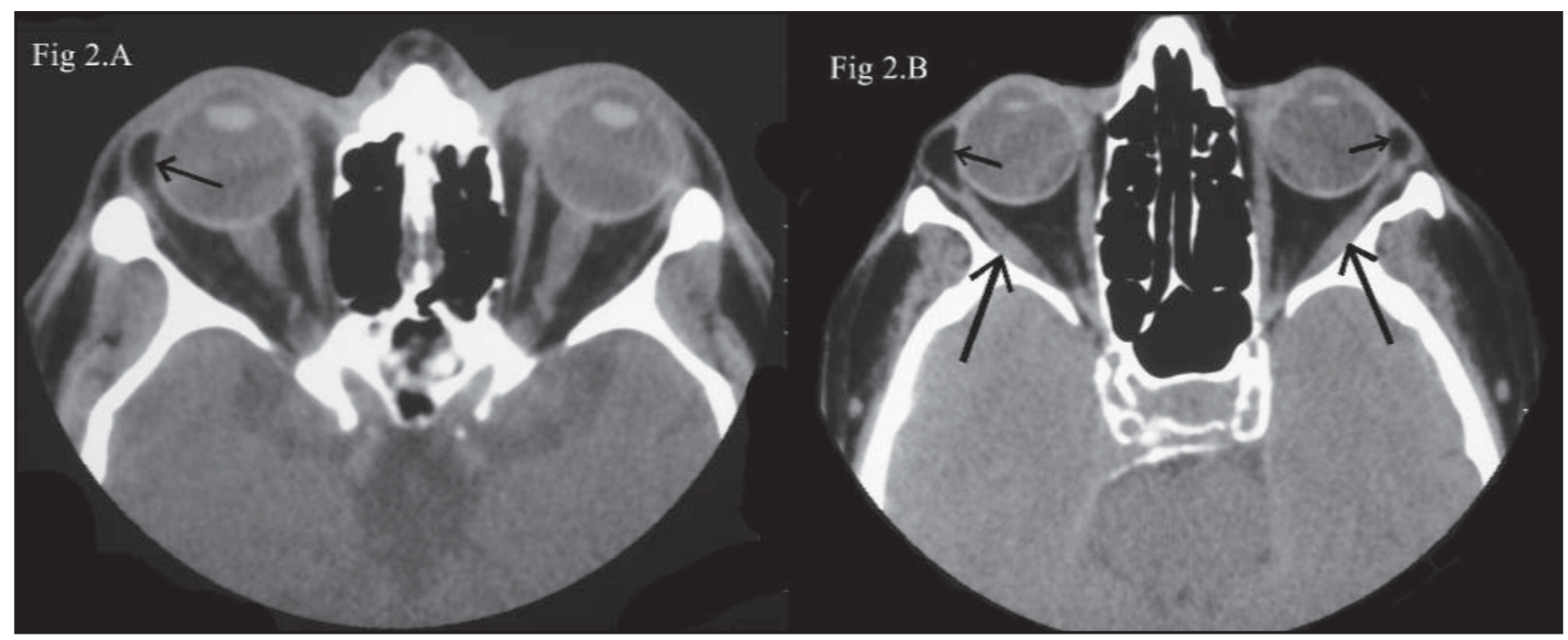

Figura 2: Tomografia computadorizada das órbitas em cortes axiais; (A) Caso 1 - Evidencia-se o prolapso de gordura orbitária na região temporal da órbita direita (seta); (B) Caso 2 - Além do prolapso de tecido gorduroso bilateralmente (setas menores) mais evidente na órbita direita, verificam-se também espessamento da musculatura extrínseca (setas maiores)

gênea, coberta por conjuntiva de superfície lisa, com alguns vasos sanguíneos e sem sinais inflamatórios ${ }^{(3.5)}$.

$\mathrm{Na}$ tomografia computadorizada das órbitas o prolapso de gordura orbitária é de baixa densidade, homogêneo, com aspecto de gordura em continuidade com a gordura intraconal ${ }^{(1-3,7)}$ e histologicamente se apresenta apenas por adipócitos maduros dispostos em lóbulos ${ }^{(3.5)}$.

O prolapso de gordura orbitária faz diagnóstico diferencial com dermolipoma ${ }^{(1,2,4,5,7)}$, prolapso da glândula lacrimal ${ }^{(2.5,7)}$, lipoma ${ }^{(2.5)}$, linfoma ${ }^{(1,3,4,7)}$, tumor de glândula lacrimal ${ }^{(3.4)}$, lipossarcoma ${ }^{(3.5)}$ e cisto dermóide ${ }^{(3,5)}$.

A oftalmopatia de Graves possui etiologia diferente, ocorre devido à reação autoimune, com inflamação dos músculos extraoculares e infiltração celular inflamatória, o que causa aumento dos adipócitos, edema e congestão vascular ${ }^{(6)}$. As principais manifestações clínicas são retração palpebral, proptose, envolvimento de tecidos moles, neuropatia óptica e miopatia restritiva ${ }^{(8)}$.

O aumento da gordura orbitária na oftalmopatia de Graves é fator primordial da exoftalmia, principalmente quando ocorre na região anterior da órbita ${ }^{(9)} \mathrm{e}$, se associado ao prolapso da gordura orbitária, torna-se importante no desencadeamento da neuropatia óptica ${ }^{(1)}$.As alterações do tecido adiposo podem acontecer isolada ou simultaneamente às do volume da musculatura extraocular ${ }^{(6,11)}$.A constatação das alterações na gordura intraorbitária e na musculatura extraocular é realizada pelos exames de imagem ${ }^{(6.9-12)}$.

O acometimento das órbitas pode ser a primeira apresentação da doença de Graves manifestando-se mesmo na ausência de evidências clínicas e bioquímicas de disfunção tireoidiana ${ }^{(6,8,12)}$. Na prática ambulatorial, essa é a forma que mais frequentemente se apresenta aos oftalmologistas ${ }^{(8)}$.

Os pacientes relatados apresentavam-se clinicamente de forma semelhante, com mesma história e exame físico mostrando elevação na região temporal da órbita direita. Os exames de imagem permitiram diferenciá-los, uma vez que o primeiro paciente apresentava apenas aumento e prolapso da gordura intraorbitária e a segunda, além dessas alterações manifestava outros sinais radiológicos da oftalmopatia de Graves, como espessamento da musculatura extrínseca e proptose. Apesar de a segunda paciente possuir características tomográficas da oftalmopatia de Graves, ela não manifestava outras alterações oftalmológicas ao exame físico ou sintomas de tireotoxicose, além disso, os exames laboratoriais evidenciaram eutireoidismo.

Na bibliografia pesquisada, o prolapso de gordura orbitária e a oftalmopatia de Graves foram relatados como enfermidades que acometeram simultaneamente as órbitas ${ }^{(3,10)}$. Não se encontrou relato na literatura ocidental abordando essas entidades clínicas como diagnósticos diferenciais. Como a oftalmopatia de Graves pode se manifestar clínica e radiologicamente apenas com aumento e prolapso da gordura orbitária, sugere-se que essas duas entidades nosológicas sejam aventadas como possíveis diagnósticos diferenciais, ressaltando que a oftalmopatia pode preceder a Doença de Graves.

\section{Abstract}

We report two cases of orbital fat prolapse. One associated with Graves' ophthalmopathy. Both patients presented 


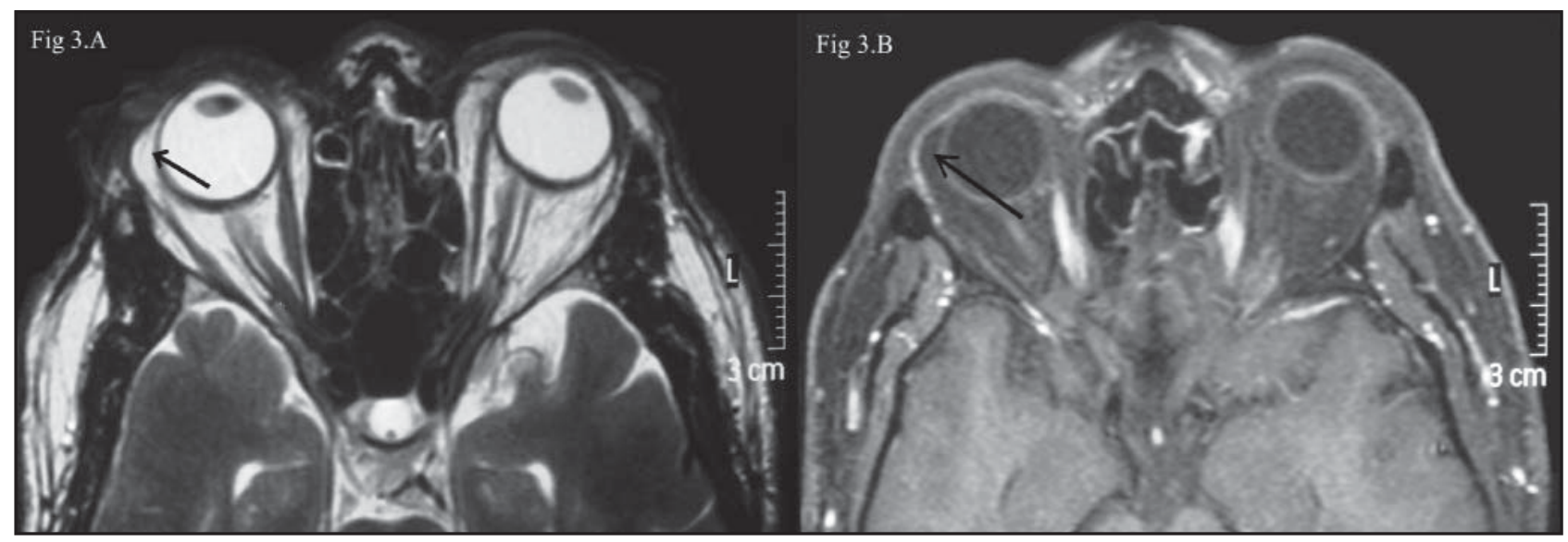

Figura 3: Caso 1 - Ressonância magnética das órbitas identificando um aumento da gordura intraorbitária (setas) que se projeta no canto temporal da órbita direita. (A) Prolapso de gordura orbitária em T2; (B) Prolapso de gordura orbitária em T1 com supressão de gordura

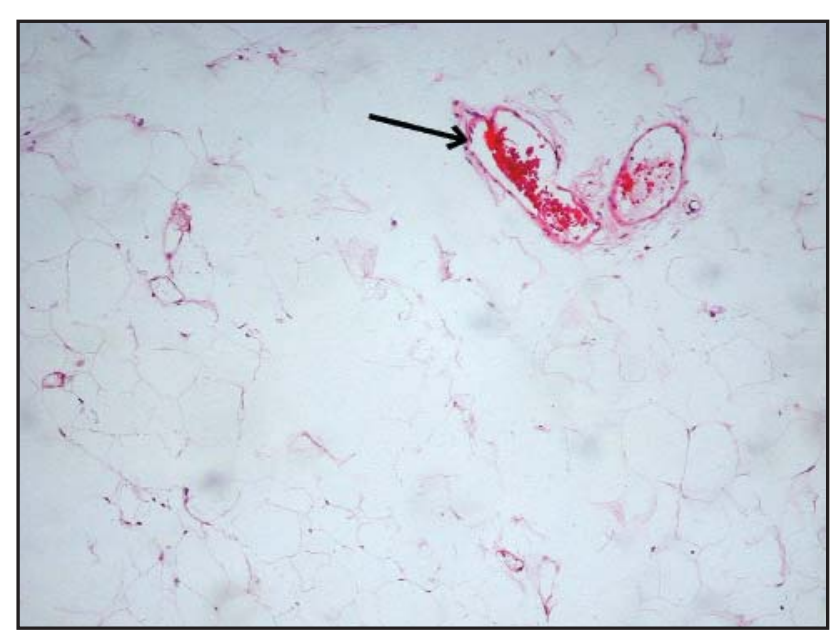

Figura 4: Caso 1 - Prolapso de gordura orbitária: a lesão é composta apenas por adipócitos maduros e capilares congestos (seta); Coloração: Hematoxilina e eosina; Aumento: 100x

similar clinical exams and an increase in intraorbital fat as seen in computerized orbital tomography. The patient with Graves' ophthalmopathy also presented an increased volume in orbital muscles in the tomography. This work seeks to include Graves' ophthalmopathy as differential diagnosys for Orbital fat prolapse.

Keywords: Ophthalmopathy; Graves'disease; Orbital diseases; Graves' ophthalmopathy; Prolapse; Adipose tissue; Case reports

\section{REFERÊNCIAS:}

1. McNab AA. Subconjunctival fat prolapse. Aust N Z J Ophthalmol. 1999;27(1): 33-6.

2. Jordan DR, Tse DT. Herniated orbital fat. Can J Ophthalmol. 1987;22:173-7.
3. Schmack I, Patel RM, Folpe AL, Wojno T, Zaldivar RA, Balzer B, et al. Subconjunctival herniated orbital fat: A benign adipocytic lesion that may mimic pleomorphic lipoma and atypical lipomatous tumor. Am J Surg Pathol. 2007;31(2):193-8.

4. Dias VG, Cintra DA, Gigante E. Prolapso de gordura orbitária bilateral associado a pterígio: relato de caso. Arq Bras Oftalmol. 2006; 69(3): 427-9.

5. Ferraz LCB, Schellini AS, Wludarski SCL, Marques MEA, Silva MRBM. Dermolipoma e prolapso de gordura orbital - duas entidades distintas. Arq Bras Oftalmol. 2002;65(3):327-31.

6. Forbes G, Gorman CA, Brennan MD, Gehring DG, Ilstrup DM, Earnest F IV. Ophthalmopathy of Graves' disease: computerized volume measurements of the orbital fat and muscle. AJNR Am J Neuroradiol. 1986;7(4):651-6.

7. Jordan DR. Orbital fat prolapse. Arch Ophthalmol. 1993;111:1583.

8. Kanski JJ. Oftalmologia clínica: uma abordagem sistemática. 5a ed. São Paulo: Elsevier; 2003.

9. Nishida Y,Tian S, Isberg B, Hayashi O, Tallstedt L, Lennerstrand G. Significance of orbital fatty tissue for exophthalmos in thyroid-associated ophthalmopathy. Graefe's Arch Clin Exp Ophthalmol. 2002;240(7):515-20.

10. Birchall D, Goodall KL, Noble JL, Jackson A. Graves ophthalmopathy: intracranial fat prolapse on CT images as an indicator of optic nerve compression. Radiology. 1996;200(1):123-7.

11. Rubin PAD, Watkins LM, Rumelt S, Sutula FC, Dallow RL. Orbital computed tomographic characteristics of globe subluxation in thyroid orbitopathy. Ophthalmology. 1998;105(11):2061-4.

12. Teixeira KISS. Contribuição da radiologia convencional no diagnóstico das exoftalmias distireoídeas [tese]. São Paulo (SP): Universidade de São Paulo; 1997.

ENDEREÇO PARA CORRESPONDÊNCIA:

Rachel Campêlo Feres

Rua do Bordalo, quadra 59, lote 10

Bairro Jardim Atlântico

CEP 74343-110 - Goiânia - GO

Tel: (62) 3546-4124 / (62) 9292-0550

Fax: (62) 3587-1535

E-mail: rachel@persogo.com.br /

kelcampelo@gmail.com 